\title{
The Design and Implementation of the Project Accounting System
}

\author{
Yuwen Liu \\ SDepartment of Teaching Affairs, Chengde Petroleum College, Chengde 067000, China \\ Liuyuwen3878@163.com
}

Keywords: Project, project accounting system, profit and loss, project budget, work breakdown structure.

\begin{abstract}
In this paper, in order to meet the management and business requirements of project management in the engineering company, the project accounting system is developed. While designing the system, we absorb the advantages of the rules for the preparation of accounting subject divide the project accounting into revenue accounting and profit and loss according to the financial management mode in com- inaction with the requirements of project accounting business innovatively design the project subject and the project amortization rule, and realize the information management of the project accounting system.
\end{abstract}

\section{Introduction}

Along with the rapid development of Chinese economy, the amount of construction project investment increasing, and the engineering accounting our country is from the stage of process management into the whole process of management. The project accounting management of engineering construction unit including the management of the early stage of the construction, the middle stage of the implementation and' the late stage of maintenance, the implementation stage including design stage, bidding stage, construction stage, completion acceptance and later stage of evaluation. [1] The construction accounting management of construction unit for construction projects including the management of the bidding stage, construction stage and completion inspection and acceptance stage. [2] At present, there are many disputes in the process of engineering accounting management, the contractor is at a disadvantage, and the contractor's project accounting management process is very complex, as a result, this problem has become more and more attention.

With the extensive application of computer technology, enterprises make use of financial software to complete the accounting work. Software contributes to the standardization of accounting as well as the promotion of financial and even enterprise management, thereby improving the management level and the efficiency of enterprises. It also improves the efficiency of accounting, reduces the working intensity of accountants while dealing with their work, minimizes working errors, and makes it easy to check accounts, etc. [3]

The rise of Internet devotes to the rapid development of information network. With the fast flow of information, resources come into integration by large quantities. By way of information network, the isolation mode of financial information within enterprises has been transferred to the network mode through which a large number of net individuals can take part in the integration of information. Such expansion makes the financial management change from decentralization to centralization as well as from the headquarters to the whole enterprise. Branch enterprises upload relative data to the ERP financial mode of headquarters through the network. Thus, with the powerful system support of enterprises, the high-level financial management can be achieved in the field of the corporate financial accounting, analysis, and control, decision-making and so on.

\section{Logic design}

However, it is the fact that most domestic enterprises use accounting software respectively and isolate their own information. Data cannot be exchanged or shared between various systems. This situation does not really reflect the advantages of information system and does not conducive to 
information management, transfer and sharing. [4] The project construction company had relied on the construction, with the rapid development of the enterprise. It also needs to be in the face of fierce industry competition and so on. How to strengthen the management of project accounting within the enterprise, to achieve the purpose of reduce the accounting of the project accounting, which would ultimately maximize the company benefit. So, the project accounting management becomes the focus of company management control. As the main content, this paper will unfold the information management research of concerned construction enterprises accounting management. Structure of project subject in Ref. [5] is shown in Table 1.

Table 1 Structure of project subject

\begin{tabular}{cccc}
\hline The first bit & \multicolumn{1}{c}{ 2nd } & third & fourth \\
\hline Subject categories & Cost to & Source to distinguish & Cost breakdown \\
distinguish & & \\
Y: The budget & 6: Main business & 1: Assets to increase & 00: other \\
H & 8: profits & 2: Assets to reduce & 01: Equipment cost \\
& 2: account & 0: other & 02: Employee compensation \\
1: Fixed assets & & 03: Ancillary expenses \\
9: The cost of & & $\ldots . .$. \\
7: Carry forward & & \\
\hline
\end{tabular}

Table 2 Merging rules of amortization

\begin{tabular}{cccc}
\hline The annual & $\begin{array}{c}\text { Marketing } \\
\text { Department }\end{array}$ & $\begin{array}{c}\text { Benefited amortize } \\
\text { department }\end{array}$ & Amortize the weight \\
\hline 2013 & This part & ERP & 1.0 \\
2013 & This part & MES & 2.0 \\
2013 & This part & BI & 1.0 \\
2013 & ERP & ERP & 1.0 \\
2013 & MES & MES & 1.0 \\
2013 & BI & BI & 1.0 \\
\hline
\end{tabular}

Table 2 shows merging rules of amortization and we can see amortization factors of project in Table 3. Enterprise financial computerization was a landmark change for financial job. It not only changed the financial personnel working condition, and improved work efficiency, but also improves quality of the financial work in accurate and standard. [6] In this thesis, design and supply chain accounting software according to the structure features and small business financial accounting work methods, in order to supply chain system this module as the breakthrough point, based on Java Web related technology, combined with financial processing related process, and make its independent to complete the enterprise raw material enter an item in an account and accounting work and forming a corresponding statements.

Table 3 Amortization factors of project

\begin{tabular}{cccc}
\hline The accounting period & department & project & Amortization factor \\
\hline 201306 & ERP & ERP project 1 & 100 \\
201306 & ERP & ERP project 2 & 200 \\
201306 & ERP & ERP project 3 & 300 \\
201306 & MES & MES project 1 & 400 \\
201306 & MES & MES project 2 & 500 \\
201306 & BI & BI project 1 & 600 \\
201306 & BI & BI project 2 & 700 \\
\hline
\end{tabular}




\section{System design}

Based on the fact that bidding gentry is the main service of a subsidiary, the author has fully learned the accounting methods of the bidding items and thus obtained much experience. On this basis, he designed and developed the accounting system of the bidding project. Prior to this, the company has already established the management system of the bidding system, achieving the all-round supervision of its bidding items. The accounting system software in this paper is developed on the basis of practical needs, which are part of the bidding company's distinguishing business and core business-the project bidding gentry, aiming at constructing a bridge between the management system and the ledger system. A unified plan of information management can enhance the business management level and help to re-plan and integrate the present system platform. It can also directly display the ledger data of the company's overall business situation in the individual bidding projects, providing more detailed and accurate financial data for the analysis of business management as well as a more substantial foundation for the leadership of the company's business decision. Simulation data of project subject is shown in Table 4.

Table 4 Simulation data of project subject

\begin{tabular}{|c|c|c|c|c|}
\hline category & department & Item no. & The project course & $\begin{array}{c}\text { The actual } \\
\text { amount/yuan }\end{array}$ \\
\hline Revenue budget & ERP & project 1 & Y6001 & 5000.00 \\
\hline Cost budget & ERP & Project 1 & Y9120 & 3000.00 \\
\hline Cost budget & ERP & Project 1 & Y9010 & 1800.00 \\
\hline $\begin{array}{c}\text { Income } \\
\text { accounting }\end{array}$ & ERP & Project 1 & H6001 & 6000.00 \\
\hline Cost accounting & ERP & Project 1 & H9120 & 2300.00 \\
\hline Cost accounting & ERP & Project 1 & H9010 & 1200.00 \\
\hline Cost accounting & ERP & Project 1 & H9810 & 300.00 \\
\hline Cost accounting & ERP & Project 1 & H9820 & 200.00 \\
\hline \multicolumn{5}{|c|}{ ERP project 1 Amortization cost $=1000 \times 100 /[(100+200+300) \times 1.0+(400+500) \times 2.0+(600+700)$} \\
\hline \multicolumn{5}{|c|}{$\times 1.0]+1000 \times 100 /(100+200+300)$} \\
\hline \multicolumn{5}{|c|}{ BI project 1 Amortization cost $=1000 \times 600 /[(100+200+300) \times 1.0+(400+500) \times 2.0+(600+700)$} \\
\hline \multicolumn{5}{|c|}{$\times 1.0+1000 \times 600 /(600+700)$} \\
\hline
\end{tabular}

Set up the system database platform and development platform, configuring development environment and make the completion of the user login function, basic data management function, warehousing management function, outbound management function and invoice management and report output function, and provide the inquiry management function.

Use the way of the unit test for testing the system function, and make system performance test and analysis test according to user needs and designing target.

This thesis uses Java web development technology to make the system implementation and JDBC as database connection technology, and uses SQLServer2005 database as data access platform, through the Tomcat6.0 web server program release, through the system test and analysis, this software can normal operation and achieve expected functions, can be put into use.

\section{Effect analysis}

This paper is mainly focused on two aspects. Firstly, it gives an overall introduction to the relevant theories and technologies of the framework for the entire accounting system, attaches great importance on the front-end development tool of Ext JS and analyzes the realization of the SSH (Struts, Spring, Hibernate)-based method. Secondly, it provides a technical analysis of the accounting network accounting system using Web service and makes a combination of the present research results at home and abroad. Thus, the relevant financial data have been uploaded to the headquarters through the network of the ERP financial modules, achieving the high-level financial management of 
corporate financial accounting, analysis, and supervision, decision-making and so on. On this basis, the paper further displays the function framework and function modules of the software and makes further discussion of the several representative types of the typical functions meanwhile offering the design and implementation of corresponding software. Diagram of the model based on the process sequence is shown in Fig. 1.

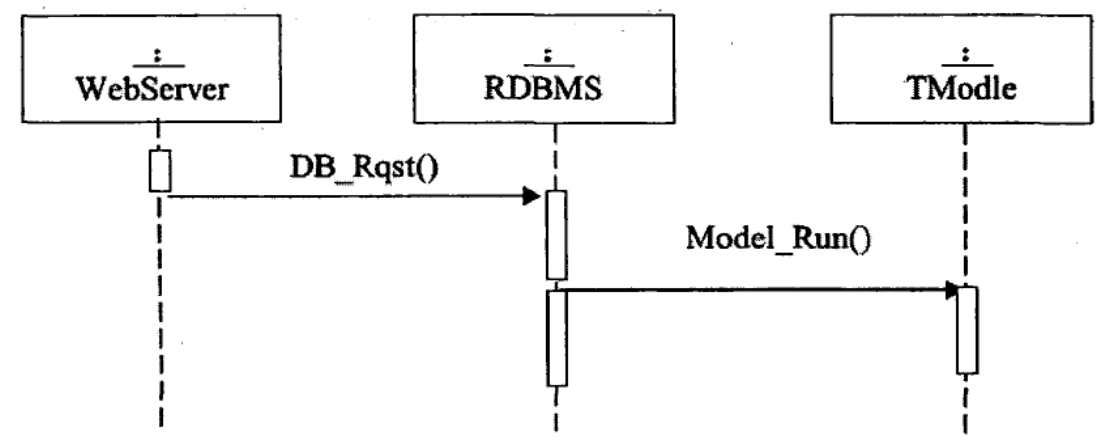

Fig. 1 Diagram of the model based on the process sequence

Since its trial operation, this system has well met the practical needs of the project accounts. To some extent, it has solved the relative problems encountered in the bidding project as well as in the accounting item, achieving good effects in practice.

\section{Conclusions}

In this paper, the implementation software is based on the client-server structure to build the project valuation business centered function structure. This paper first summarized the greatly main concept, theory and application of the valuation of today's complex project and the budget management; then respectively established the functional requirements and system use cases based on the main categories of functions to software system, including the whole process valuation management function of construction engineering projects, project valuation and fee schedule management function, the quantity list management function, the project budget, its quota management functions, project valuation analysis and project investment budget support functions, etc. analyzed the corresponding functional requirements and the use case model in entail, also analyzed and discussed the quantitative calculation and management model methods by use the project valuation combined with the characteristics of the project in detail, such as investment estimation model based on output efficiency function, the accounting allocation model based on the project decomposition, combination treatment, etc., these models and plenty of norm and index parameters management are the operation foundation of the software system. Finally, this paper discusses the design of the software system, including the database logical structure, the relationship between the main data table, the design of the main functional features of application serer logic layer, corresponding software implementation are discussed according to the functional level.

\section{References}

[1] Kruchten P. A Flexible Framework for Integrate Heterogeneous Functional Components in Supply Chain. IEEE Software. 2012, 23(2): 22-30.

[2] Goldsmith A. Supply Chain Analysis and Practice. N-Y: Prentice-Hall Inc, 2010: 30-43.

[3] Ying H, Chung J-H. A Web Services-based Framework for Business Integration Solutions. Electronic Commerce Research and Applications, 2011, 11(2):115-126.

[4] Yang J, Papazoglou M. Service Components for Managing the Life-cycle of Service Compositions. Information System, 2009, 29(1): 97-125.

[5] Kirchsteiger C. Technical communication on status in developing a comipass for risk assessment. Safety Science, 2011, 23(3): 120-126. 
[6] Mohamed, KA et al. Contuactor's decision for bid profit reduction. Within opportunistic bidding behavior of claims recovery. International Journal of Project Manage, 2009, 22(12): 1-15. 